\title{
PENERIMAAN DOSIS ORGAN KRITIS PADA PEMERIKSAAN CEREBRAL DSA DENGAN BIPLANE C-Arm
}

\author{
${ }^{1}$ Adelina Oinike, S.Si; ${ }^{1}$ Guntur Winarno, S.Si.,M.Si; ${ }^{1}$ Purwatinigsih, S.Si., M.Sc. \\ ${ }^{1}$ Universitas Nasional,Indonesia \\ Corresponding author: Adelina Oinike, S.Si \\ Email: nikeadelina@gmail.com
}

\begin{abstract}
Background:Cerebral Digital Substraction Angiography (DSA) screening is widely used in hospitals to find out even treat strokes and vascular abnormalities. During the examination, the patient received radiation from a $\mathrm{C}$ Arm Biplane. The estimated dose received by the patient has been measured on the monitor screen which is the DAP value, but to find out the actual dose received by the patient, it is necessary to measure directly using the TLD attached to the patient's body during the examination.
\end{abstract}

Method: Measurement of critical organ dose is done by attaching TLD-100 chips on the surface of the eye, thyroid, and gonad to 6 different patients.

Results: The purpose of this study was to measure and evaluate the amount of dose received by the patient's critical organs during Cerebral DSA examination.

Conclusion: The results showed that (1) the amount of eye dose received by the patient during cerebral DSA examination was $23.01 \mathrm{mGy}$ to $144,787 \mathrm{mGy}$. (2) the amount of thyroid dose received by the patient during cerebral DSA examination is $15,348 \mathrm{mGy}$ to $76,162 \mathrm{mGy}$. (3) the amount of gonad dose received by the patient during Cerebral DSA examination is $0.09 \mathrm{mGy}$ to $229,848 \mathrm{mGy}$. (4) DAP values during Cerebral DSA examination obtained values in the range of $77088 \mathrm{mGycm} 2$ to $167718 \mathrm{mGycm} 2$.

Keywords: Dose, Thermoliminisence Dosimeter (TLD); Dose Area Product (DAP); Entrance Surface Dose (ESD)

\section{Pendahuluan}

Strok merupakan penyebab kematian dan kecacatan utama di banyak negara termasuk Indonesia. Pada penelitian yang dilakukan tahun 2009, nilai Case Fatality Rate (CFR) penyakit strok adalah yang tertinggi yaitu sebesar 12,68\% (Kemenkes RI, 2012). Pemeriksaan Cerebral DSA sangat penting untuk mendiagnosa maupun terapi pada pasien strok dan pasien dengan kelainan pembuluh darah. Pada pemeriksaan ini, lamanya waktu fluoroskopi yang dibutuhkan bergantung pada kompleksitas kasus pasien dan pengalaman dokter pemeriksa. Oleh karenanya, lamanya waktu fluoroskopi sangat bervariasi antar satu pasien dengan pasien lainnya. Dosis tinggi yang diterima pasien berasal dari dosis primer dan hamburannya. Peningkatan dosis pasien akan memperbesar peluang terjadinya efek biologi (Cember, dkk. 1983). Organ kritis dalam pemeriksaan Cerebral DSA adalah mata, gonad dan tyroid karena perannya yang sangat vital bagi kelangsungan hidup seseorang baik secara psikis maupun psikologi. Efek biologi pada mata dapat berupa katarak mata untuk dosis yang melampaui dosis ambang sekitar 0,5 Gy (ICRP, 2011). Pengukuran dosis organ kritis dan dosis permukaan dilakukan dengan TLD (Thermo Luminescence Dosimeter). Tujuannya adalah untuk mengetahui dan mengevaluasi penerimaan dosis organ kritis pada pasien dengan pemeriksaan Cerebral DSA.

\section{Prinsip Fluoroskopi}

Mode fluoroskopi adalah pencitraan secara real time untuk mengevaluasi objek yang tetap atau diam. Pada penyinaran otomatis, kendali penyinaran atau sistem $\mathrm{ABC}$ akan menyesuaikan pilihan dosis dan banyaknya fps yang kita butuhkan agar kualitas citra organ baik. $\mathrm{Hal}$ ini memancing $\mathrm{kVp} / \mathrm{mA}$ dan kecepatan pulsa (pulsa per second) yang dibangkitkan oleh generator sinar $\mathrm{X}$ mengikuti pengaturan yang kita pilih sebelumnya. Rekaman citra dengan mode fluoroskopi (continous) pada reseptor image intensifier akan dikonversi menjadi sinyal digital sementara untuk reseptor flat panel detector, sinyal digital langsung diambil dari file citra digital. File citra digital akan dikirim ke monitor atau komputer untuk diolah dan dievaluasi. Mode akuisisi atau cine adalah pencitraan secara real time untuk merekam objek yang bergerak. Pada umumnya untuk mengevaluasi aliran kontras media yang masuk kedalam pembuluh darah. 
Mode ini diatur untuk menghasilkan kualitas citra terbaik agar tidak ada kesalahan dalam mengevaluasi pembuluh darah tersebut. Dengan kendali otomatis sistem $\mathrm{ABC}$, kecepatan pulsa rendah akan memancing $\mathrm{kVp} / \mathrm{mA}$ sangat tinggi agar intensitas sinyal yang diterima reseptor cukup untuk dikonversi menjadi citra visual dengan kualitas maksimal. Rekaman citra tunggal mode cine, dihasilkan dari akuisisi beberapa frame menjadi satu run. Akuisisi dilakukan dengan bantuan algoritma atau sebuah perangkat lunak untuk mengurangi noise sehingga menghasilkan kontras lebih baik dan citra yang lebih jernih.

\section{ESD (Entrance Surface Dose)}

ESD adalah salah satu kuantitas yang digunakan dalam diagnostik untuk menyatakan dosis radiasi yang diterima obyek radiasi (phantom atau pasien) yang diukur pada pusat berkas utama di permukaan obyek. ESD biasanya diukur dalam satuan $\mathrm{mGy}$, dosis yang diserap pada permukaan kulit pasien di pusat lapangan penyinaran, termasuk radiasi hamburan balik dari organ di bawah kulit (Vienna, 2003). Kuantitas lain yang sering digunakan adalah dosis insiden (incident air kerma). Perbedaan antara ESD dengan incident air kerma adalah ESD sudah termasuk dosis radiasi hambur (backscatter) sementara dosis insiden tidak, sehingga ESD akan selalu lebih besar dari dosis insiden. Pengkuran ESD secara langsung dilakukan dengan menggunakan TLD, sementara pengukuran dosis insiden biasanya menggunakan detektor yang tidak peka terhadap backscatter (Vienna, 2007). incident air kerma (IAK) merupakan dosis serap di udara yang diukur pada sebuah titik permukaan suatu obyek, pada jarak tertentu dari fokus pesawat sinar-X di pusat lapangan penyinaran tetapi tidak termasuk radiasi hambur balik.

\section{DAP (Dose Area Product)}

Dose area product (DAP) diartikan sebagai dosis serap di udara pada area berkas sinar-X yang tegak lurus dengan pusat berkas dikalikan dengan berkas area bidang yang sama. Hasil pengukuran umumnya dinyatakan dalam $\mathrm{Gycm}^{2}$ dan radiasi hambur dari pasien tidak diperhitungkan. Untuk mengukur DAP digunakan DAP meter yang merupakan peralatan opsional sebagai tambahan pada pesawat tersebut. Detektor pada DAP meter adalah bilik ionisasi (ionization chamber) transparan yang dihubungkan dengan elektrometer yang akan merespon total charge yang terkumpul di area chamber. Bilik ionisasi biasanya diletakkan di dekat fokus tabung dimana area berkas sinar-X relatif kecil dan dose rate relatif tinggi. Plat bilik ionisasi yang transparan tidak mengganggu jalannya pemeriksaan sehingga penggunaannya dapat dilakukan sepanjang waktu pemeriksaan dan informasi dapat diberikan secara real time.

\section{TLD (Thermoluminescene Dosimeter)}

Peristiwa luminesensi dengan bantuan pemanasan dari luar disebut termoluminesensi (Attix, 1986). TLD merupakan dosimeter yang prinsip kerjanya berdasarkan fenomena termoluminesensi. Material TLD pada umumnya merupakan material kristalin yang memiliki impuritas yang akan mengakibatkan terbentuknya tambahan level energi diantara level valensi dan level konduksi. Tambahan tingkat energi yang dekat dengan tingkat valensi disebut perangkap lubang. Pada saat TLD menerima radiasi, elektron menerima energi dan tereksitasi meloncat ke pita konduksi. Selanjutnya elektron tersebut akan turun ke perangkap elektron. Muatan positif yang ditinggalkan oleh elektron akan menempati tingkat energi pada perangkap lubang. Dalam pembacaan, TLD dipanaskan untuk membebaskan elektron dari perangkapnya dan naik ke pita konduksi yang selanjutnya akan meloncat turun dan bersatu kembali dengan lubang disertai emisi cahaya yang disebut termoluminesensi. Intensitas total termoluminesensi sebanding dengan jumlah elektron yang terjebak dan sebanding pula dengan energi radiasi yang diserap. Dengan demikian intensitas cahaya yang diemisikan dari kristal termoluminesensi akan berbanding lurus dengan dosis radiasi. TLD reader mengubah intensitas cahaya menjadi sinyal yang diukur dengan satuan $\mathrm{nC}$ (nano coulomb). Pengukuran dilakukan sebanyak dua kali proses untuk chip TLD. Pengukuran pertama adalah membaca intensitas termoluminesensi total, sedangkan pengukuran kedua adalah membaca intensitas termoluminesensi latar. Intensitas termoluminesensi bersih merupakan hasil pengurangan intensitas termoluminesensi total dengan intensitas termoluminesensi latar. Perhitungan dosis radiasi (D) yang diterima TLD dilakukan dengan formula sebagai berikut: 


$$
D=T L(n C) x F k\left(\frac{\mu G y}{n C}\right)
$$

$F_{k}$ adalah faktor kalibrasi yang merupakan fungsi energi, sehingga TLD harus dikalibrasi terlebih dahulu dengan jenis radiasi yang akan diukur.

\section{Efek Biologi Terdahap Radiasi}

Efek radiasi dapat dibedakan menjadi 2, yaitu efek stokastik dan efek deterministik. Efek deterministik memiliki dosis ambang dan akibat yang ditimbulkan sesuai dengan dosis yang diterima sementara efek stokastik tidak memiliki dosis ambang. Nilai ESD untuk banyak prosedur fluoroskopi intervensional yang diteliti memiliki nilai yang mendekati bahkan diatas $2 \mathrm{~Gy}$, yaitu nilai dosis ambang untuk menimbulkan eritema pada kulit (Miller dkk, 2003). Adapun Efek stokastik yang bisa terjadi pada pasien misalnya kanker, efek hereditary (efek terlihat pada keturunan yang lahir dari orang tua yang salah satu atau keduanya mendapatkan radiasi sebelum konsepsi) dan efek pada fetus (Faulkner dkk, 2009). Efek yang perlu diwaspadai untuk prosedur intervensional fluoroskopi adalah keduanya. Mata adalah organ penglihatan manusia, di dalamnya terdapat lensa mata yang sangat sensitif dengan radiasi. Lensa mata yang terpapar

dengan dosis minimal 0,5 Gy akan mengalami kekeruhan yang teramati. Lensa mata yang terpapar dosis 2 Gy - 10 Gy dalam kurun waktu 6 bulan akan mengalami katarak karena radiasi (ICRP, 2011). Adapun radiosensitivitas gonad antara pria dan wanita berbeda sehingga dosis ambangnya pun berbeda. Pada ovarium, nilai ambang untuk kemandulan sementara sebesar 0,65 Gy dan kemandulan permanen pada 2,5 Gy - 6 Gy. Pada testis, nilai ambang untuk kemandulan sementara sebesar 0,15 Gy dan kemandulan permanen pada 3,5 Gy - 6 Gy (ICRP, 1991). Efek stokastik berupa kanker tiroid yang banyak terjadi sebagai akibat paparan radiasi tindakan radioterapi (sampai 5 Gy). Paparan radiasi pada kelenjar tiroid pada usia kanak-kanak akan menyebabkan individu tersebut menderita kanker tiroid setelah dewasa (ICRP, 1991).

\section{Metode}

Pengambilan data dosis organ kritis pada pemeriksaan cerebral DSA diukur dengan menggunakan alat ukur radiasi berupa chips
TLD-100 yang diletakkan pada mata kanan, mata kiri, tiroid, gonad (pada perempuan di ovarium kanan-kiri dan pada laki-laki di scrotum) pasien. Selama pemeriksaan cerebral DSA berlangsung, chips TLD-100 akan terpapar sinar-X secara langsung maupun tidak langsung. Chips TLD100 yang digunakan dapat mengukur dosis radiasi yang diserap pasien termasuk dosis hambur balik yang terjadi, sehingga dosis yang terekam adalah dosis serap pada pasien. Metode penelitian ini bersifat eksperimental dengan melakukan pengukuran langsung pada 6 orang pasien pada rentang waktu 27 April 2015 s.d 29 Mei 2015. Pembacaan TLD-100 dilakukan dengan TLD reader merk Harshaw Seri 2000 A/B. Data yang dianalisis di penelitian ini adalah dosis serap pada mata kanan, mata kiri, tiroid, gonad (pada perempuan di ovarium kanan-kiri dan pada laki-laki di scrotum) pasien. Selanjutnya nilai dosis pada mata kanan-kiri dan ovarium kanan-kiri akan diambil nilai mean-nya sebagai nilai dosis mata dan nilai dosis gonad perempuan. Nilai dosis pada setiap organ kritis yang telah diukur akan dibandingkan dengan nilai dosis pada Diagnostic Reference Level's (DRL's) berbagai Negara. Setiap nilai Dose Area Product (DAP) yang didapatkan akan dibandingkan dengan nilai DAP pada Diagnostic Reference Level's (DRL's).

\section{Hasil dan Pembahasan}

Hasil pengukuran dosis organ kritis menggunakan TLD di mata, tiroid dan gonad pasien.

Tabel 1. Dosis Organ Kritis Pada Pemeriksaan Cerebral DSA

\begin{tabular}{|c|c|c|c|c|c|c|c|c|c|c|}
\hline \multirow[b]{2}{*}{$\begin{array}{l}\mathbf{N} \\
\mathbf{o}\end{array}$} & \multirow{2}{*}{$\begin{array}{l}\mathbf{S} \\
\mathbf{e} \\
\mathbf{x}\end{array}$} & \multirow{2}{*}{$\begin{array}{l}\text { Be } \\
\text { rat } \\
\text { Ba } \\
\text { da } \\
\mathbf{n} \\
(\mathbf{k} \\
\text { g) }\end{array}$} & \multicolumn{2}{|c|}{$\begin{array}{c}\text { Faktor } \\
\text { Eksposi }\end{array}$} & \multicolumn{6}{|c|}{ Dosis Pasien (mGy) } \\
\hline & & & $\mathbf{k V}$ & $\begin{array}{l}\text { m } \\
\text { As }\end{array}$ & $\begin{array}{l}\text { Mata } \\
\text { Kanan }\end{array}$ & $\begin{array}{c}\text { Mata } \\
\text { Kiri }\end{array}$ & $\begin{array}{c}\text { Tiroi } \\
\mathbf{d}\end{array}$ & $\begin{array}{c}\text { Ovariu } \\
\text { m } \\
\text { Kanan }\end{array}$ & $\begin{array}{c}\text { Ovari } \\
\text { um } \\
\text { Kiri }\end{array}$ & $\begin{array}{c}\text { Scrot } \\
\text { um }\end{array}$ \\
\hline 1 & $\mathrm{~L}$ & 66 & 80 & 48 & 35.262 & $\begin{array}{c}102.58 \\
2\end{array}$ & $\begin{array}{c}26.58 \\
7\end{array}$ & & & 0.062 \\
\hline 2 & $\mathrm{P}$ & 62 & 80 & 44 & 54.643 & $\begin{array}{c}234.93 \\
2\end{array}$ & $\begin{array}{c}76.16 \\
2\end{array}$ & 0.093 & 0.356 & \\
\hline 3 & $\mathrm{P}$ & 79 & 80 & 35 & 29.135 & $\begin{array}{c}111.64 \\
8\end{array}$ & $\begin{array}{c}15.34 \\
8\end{array}$ & 0 & 0.018 & \\
\hline 4 & $\mathrm{P}$ & 45 & 80 & 39 & 30.026 & $\begin{array}{c}124.74 \\
8\end{array}$ & $\begin{array}{c}27.48 \\
1\end{array}$ & 0.146 & 0.143 & \\
\hline 5 & $\mathrm{~L}$ & 60 & 80 & 53 & 13.967 & 32.053 & $\begin{array}{c}51.06 \\
7\end{array}$ & & & $\begin{array}{c}229.8 \\
48\end{array}$ \\
\hline 6 & $\mathrm{P}$ & 48 & 80 & 55 & 72.12 & 131.36 & $\begin{array}{c}40.34 \\
4\end{array}$ & 229.602 & 0.055 & \\
\hline
\end{tabular}

Di dalam tabel 1 didapatkan nilai dosis mata kiri jauh lebih besar dari dosis mata kanan. Rentang nilai dosis mata kanan 13,967 mGy 
hingga $72,12 \mathrm{mGy}$ dan rentang nilai dosis mata kiri $32,053 \mathrm{mGy}$ hingga $234,932 \mathrm{mGy}$. Hal ini disebabkan oleh penggunaan alat Biplane $C$-arm. Selama pemeriksaan Cerebral DSA berlangsung, pasien mendapatkan paparan radiasi dari arah depan dan samping. Letak tube pada lateral $C$ arm yang terletak disisi kiri pasien yang menyebabkan tingginya nilai dosis mata kiri. Nilai dosis tiroid besarnya bervariasi dengan rentang dosis 15,348 mGy hingga 76,162 mGy. Letak tiroid yang berada pada daerah arteri carotis dan dekat dengan arcus Aorta. Hal ini menyebabkan waktu fluoroskopi yang diperlukan untuk mengarahkan catheter pada pembuluh darah yang diperiksa berubah-ubah. Tingkat kesulitan dalam melakukan maneuver pembuluh darah dan adanya kelainan stenosis pada bagian proximal pembuluh darah yang diperiksa akan meningkatkan total waktu paparan fluoroskopi. Nilai dosis gonad besarnya bervariasi pada perempuan maupun laki-laki. Nilai dosis gonad terbesar didapatkan pada scrotum sebesar 229,848 mGy. Letak gonad, baik pada laki-laki dan perempuan dekat dengan daerah puncture pada inguinal arteri. Seluruh sample pasien ini, dilakukan puncture pada daerah inguinal femoral kanan. Ada dua nilai dosis gonad yang tinggi yaitu pada scrotum Tn. E dan pada ovarium kanan Ny. F. Hal ini dapat disebabkan oleh tingkat kesulitan dalam melakukan puncture, memasukkan guide wire dan cathether yang berbeda-beda.

Dosis Organ Kritis Pada Pemeriksaan Cerebral DSA dan faktor resiko radiasi.

Tabel 2. Dosis Organ Kritis Pada Pemeriksaan Cerebral DSA dan faktor resiko radiasi

\begin{tabular}{|c|c|c|c|c|c|c|c|c|c|}
\hline \multirow{2}{*}{$\begin{array}{l}\mathbf{N} \\
\mathbf{o}\end{array}$} & \multirow{2}{*}{$\begin{array}{l}\mathbf{S} \\
\mathrm{e} \\
\mathrm{x}\end{array}$} & \multicolumn{2}{|c|}{$\begin{array}{c}\text { Faktor } \\
\text { Eksposi }\end{array}$} & \multirow{2}{*}{$\begin{array}{c}\text { Juml } \\
\text { ah } \\
\text { Fra } \\
\text { me }\end{array}$} & \multirow{2}{*}{$\begin{array}{c}\text { Waktu } \\
\text { Fluorosc } \\
\text { opy } \\
\text { Total } \\
\text { (min) }\end{array}$} & \multirow{2}{*}{$\begin{array}{c}\text { DAP } \\
(\mathbf{m G} \\
\mathrm{ycm}^{2} \\
)\end{array}$} & \multicolumn{3}{|c|}{ Dosis Pasien (mGy) } \\
\hline & & $\mathbf{k V}$ & $\begin{array}{l}\text { m } \\
\text { As }\end{array}$ & & & & Mata & Tiroid & Gonad \\
\hline 1 & $\mathrm{~L}$ & 80 & 48 & 463 & 6.37 & $\begin{array}{c}8637 \\
3\end{array}$ & $\begin{array}{c}68.92 \\
2\end{array}$ & 26.587 & 0.062 \\
\hline 2 & $\mathrm{P}$ & 80 & 44 & 326 & 9.01 & $\begin{array}{c}1677 \\
18 \\
\end{array}$ & $\begin{array}{c}144.7 \\
87 \\
\end{array}$ & 76.162 & 0.224 \\
\hline 3 & $\mathrm{P}$ & 80 & 35 & 375 & 5.26 & $\begin{array}{c}1012 \\
24\end{array}$ & $\begin{array}{c}70.39 \\
2\end{array}$ & 15.348 & 0.009 \\
\hline 4 & $\mathrm{P}$ & 80 & 39 & 205 & 7.25 & $\begin{array}{c}7708 \\
8 \\
\end{array}$ & $\begin{array}{c}77.38 \\
7 \\
\end{array}$ & 27.481 & 0.1445 \\
\hline 5 & $\mathrm{~L}$ & 80 & 53 & 296 & 16.51 & $\begin{array}{c}1014 \\
30\end{array}$ & 23.01 & 51.067 & 229.848 \\
\hline 6 & $\mathrm{P}$ & 80 & 55 & 268 & 7.5 & $\begin{array}{c}8555 \\
5 \\
\end{array}$ & $\begin{array}{c}101.7 \\
4 \\
\end{array}$ & 40.344 & 114.828 \\
\hline \multicolumn{4}{|c|}{ Rerata } & $\begin{array}{c}322.1 \\
67\end{array}$ & 8.65 & $\begin{array}{c}1032 \\
31.32 \\
9\end{array}$ & $\begin{array}{c}81.03 \\
967\end{array}$ & 39.498 & 57.519 \\
\hline
\end{tabular}

Berdasarkan tabel 2 dapat dilihat ada beberapa faktor resiko radiasi yang terdapat pada pemeriksaan Cerebral DSA diantaranya: faktor eksposi, jumlah frame, total waktu fluoroskopi, dan DAP terhadap dosis organ kritis yang diukur. Korelasi antara faktor resiko radiasi dengan nilai dosis organ kritis yang disebutkan diatas belum dapat dievaluasi. Hal ini disebabkan oleh terbatasnya jumlah data yang diperoleh.

Dosis mata dibawah ini dibandingkan dengan nilai DRL pemeriksaan Kepala AP dari berbagai Negara seperti tertera pada tabel 3.

Tabel 3. Dosis Mata dengan Menggunakan TLD dan DRL's Kepala AP

\begin{tabular}{|c|c|c|c|c|c|}
\hline Pasien & $\begin{array}{c}\text { Dosis } \\
(\mathrm{mGy})\end{array}$ & $\begin{array}{c}\text { DRL's } \\
\text { United } \\
\text { Kingdo } \\
m \\
(\mathrm{mGy})\end{array}$ & $\begin{array}{c}\text { DRL's } \\
\text { Austra } \\
\text { lian } \\
(\mathrm{mGy})\end{array}$ & $\begin{array}{c}\text { DRL's } \\
\text { Europea } \\
n \\
\text { Commis } \\
\text { sion } \\
(\mathrm{mGy})\end{array}$ & $\begin{array}{c}\text { DRL's } \\
\text { Japan } \\
(\mathrm{mGy})\end{array}$ \\
\hline Tn. A & 68.922 & 1.8 & 3 & 5 & 3 \\
\hline Ny. B & 144.788 & 1.8 & 3 & 5 & 3 \\
\hline Ny. C & 70.392 & 1.8 & 3 & 5 & 3 \\
\hline Ny. D & 77.387 & 1.8 & 3 & 5 & 3 \\
\hline Tn. E & 23.010 & 1.8 & 3 & 5 & 3 \\
\hline Ny. F & 101.740 & 1.8 & 3 & 5 & 3 \\
\hline Rerata & 81.04 & 1.8 & 3 & 5 & 3 \\
\hline
\end{tabular}

Dosis tiroid dibawah ini dibandingkan dengan nilai DRL pemeriksaan Lumbal AP dari berbagai Negara seperti tertera pada tabel 4

Tabel 4. Dosis Tiroid dengan Menggunakan TLD dan DRL's Lumbal AP

\begin{tabular}{|c|c|c|c|c|c|}
\hline Pasien & $\begin{array}{c}\text { Dosis } \\
\text { Penelitian } \\
(\mathrm{mGy})\end{array}$ & $\begin{array}{c}\text { DRL's } \\
\text { United } \\
\text { Kingdom } \\
(\mathrm{mGy})\end{array}$ & $\begin{array}{c}\text { DRL's } \\
\text { Australia } \\
\text { (mGy) }\end{array}$ & $\begin{array}{c}\text { DRL's } \\
\text { European } \\
\text { Commissi } \\
\text { on (mGy) }\end{array}$ & $\begin{array}{c}\text { DRL's } \\
\text { Japan } \\
\text { (mGy) }\end{array}$ \\
\hline Tn. A & 26.587 & 5.7 & 6 & 10 & 4 \\
\hline Ny. B & 76.162 & 5.7 & 6 & 10 & 4 \\
\hline Ny. C & 15.348 & 5.7 & 6 & 10 & 4 \\
\hline Ny. D & 27.481 & 5.7 & 6 & 10 & 4 \\
\hline Tn. E & 51.067 & 5.7 & 6 & 10 & 4 \\
\hline Ny. F & 40.344 & 5.7 & 6 & 10 & 4 \\
\hline Rerata & 39.498 & 5.7 & 6 & 10 & 4 \\
\hline
\end{tabular}

Dosis gonad dibawah ini dibandingkan dengan nilai DRL pemeriksaan Pelvis AP dari berbagai Negara seperti tertera pada tabel 5. 
Tabel 5. Dosis Gonad dengan Menggunakan TLD dan DRL's Pelvis AP

\begin{tabular}{|c|c|c|c|c|}
\hline \multirow{2}{*}{ Pasien } & Penelitian & $\begin{array}{c}\text { DRL's United } \\
\text { Kingdom }\end{array}$ & $\begin{array}{c}\text { DRL's } \\
\text { Australian }\end{array}$ & DRL's Japan \\
\cline { 2 - 5 } & $\begin{array}{c}\mathrm{DAP} \\
\left(\mathrm{Gycm}^{2}\right) / \mathrm{min}\end{array}$ & $\begin{array}{c}\mathrm{DAP} \\
\left(\mathrm{Gycm}^{2}\right) / \mathrm{min}\end{array}$ & $\begin{array}{c}\mathrm{DAP} \\
\left(\mathrm{Gycm}^{2}\right) / \mathrm{min}\end{array}$ & $\begin{array}{c}\mathrm{DAP} \\
\left(\mathrm{Gycm}^{2}\right) / \mathrm{min}\end{array}$ \\
\hline Tn. A & 13.559 & 5.361 & 6.429 & 0.02 \\
\hline Ny. B & 18.615 & 5.361 & 6.429 & 0.02 \\
\hline Ny. C & 19.244 & 5.361 & 6.429 & 0.02 \\
\hline Ny. D & 10.633 & 5.361 & 6.429 & 0.02 \\
\hline Tn. E & 6.144 & 5.361 & 6.429 & 0.02 \\
\hline Ny. F & 11.407 & 5.361 & 6.429 & 0.02 \\
\hline Rerata & 13.267 & 5.361 & 6.429 & 0.02 \\
\hline
\end{tabular}
dosis terukur jauh lebih besar dibandingkan dengan nilai rerata dosis pada pemeriksaan pembandingnya. Hal ini disebabkan pada pemeriksaan Cerebral DSA kita menggunakan prinsip fluoroskopi yang dilakukan secara continue atau terus-menerus. Pada teknik pemeriksaan Digital Substraction Angiography juga terdapat teknik substraksi yang memerlukan energi radiasi yang cukup tinggi. Teknik pengambilan gambar atau eksposi yang dilakukan terdiri dari beberapa frame yang digabungkan dalam satu run tertentu. Nilai ambang batas mata untuk resiko katarak sebesar $0,5 \mathrm{~Gy}$ atau $500 \mathrm{mGy}$ dalam sekali pemeriksaan (ICRP, 2011). Nilai dosis mata tertinggi yang didapatkan sebesar 144,787 mGy. Nilai ambang tiroid sebesar 5Gy atau 5000mGy (ICRP, 1991). Nilai dosis tiroid tertinggi yang didapatkan sebesar 76,162 mGy.]. Nilai ambang sterilitas sementara pada gonad laki-laki sebesar $0,15 \mathrm{~Gy}$ atau $150 \mathrm{mGy}$ sedangkan untuk nilai ambang sterilitas sementara pada gonad perempuan sebesar $0,65 \mathrm{~Gy}$ atau $650 \mathrm{mGy}$ (ICRP, 1991). Nilai dosis organ kritis yang didapatkan dalam penelitian penulis masingmasing nilainya masih dalam batas aman dibandingkan dengan nilai ambang dosis untuk gonad dan tirod menurut ICRP 60 (ICRP, 1991). serta dosis untuk mata menurut ICRP 103 (ICRP, 2011).

Nilai Dose Area Product (DAP/min) dengan DRL's pada Pemeriksaan Cerebral Digital Substraction Angiography.
Tabel 6 Nilai Dose Area Product (DAP/min) dengan DRL's

Berdasarkan tabel 6 didapatkan bahwa nilai DAP/min pada pemeriksaan Cerebral DSA nilainya relatif jauh lebih besar dibandingkan dengan nilai DAP/min dari DRL's. Persentase perbedaan besarnya nilai rerata $\mathrm{DAP} / \mathrm{min}$ pada pemeriksaan Cerebral DSA masing-masing sebesar 247,5\% terhadap DRL's United Kingdom, 206,4\% terhadap DRL's Australian, dan 66335\% terhadap DRL's Japan. Waktu paparan fluoroskopi dan pengukuran DAP merupakan faktor prediksi yang baik untuk mengamati dosis yang diterima oleh pasien. Pencatatan waktu paparan fluoroskopi dan nilai DAP pada setiap pasien pemeriksaan Cerebral DSA dan prosedur fluoroskopi intervensional lainnya wajib untuk dicatat (Chida Koichi, 2006).

\section{Simpulan}

Nilai dosis organ kritis yang didapatkan dalam pengukuran ini nilainya masing-masing masih dibawah nilai batas ambang yang direkomendasikan. Waktu fluoroskopi dan banyaknya jumlah frame dipengaruhi oleh kompleksitas kasus dan keahlian dokter pemeriksa yang berbanding linear dengan bertambahnya nilai DAP terukur dan besarnya dosis yang akan diterima oleh pasien. Sebaiknya penelitian dilakukan juga untuk fluoroskopi dengan merk lain, mengingat setiap peralatan fluoroskopi memiliki spesifikasi khusus dan agar diberikan perhatian khusus kepada pasien yang kemungkinan menjalani ulangan pemeriksaan lebih dari satu kali untuk mengurangi efek stokastik. 


\section{Daftar Pustaka}

Attix, Frank H, Introduction to Radiological Physics and Radiation Dosimetry, John Wiley \& Sons, Newyork, 1986.

Cember, Herman. 1983. Introduction to Health Physics. New York, Pergamon Press Inc.

Chida Koichi, Saito Haruto., et al, Relationship Between Fluoroscopic Time, Dose-Area Product, Body Weight, and Maximum radiation Skin Dose in Cardiac Interventional Procuderes, American Journal of Poentgenology: 186, 2006, 774-778 March 2006.

Faulkner, K, Radiation Effects from Diagnostic and Interventional Radiology. Paper presented at Workshop on Quality Assurance in Diagnostic and Interventional Radiology in Jakarta, Januari 2009.

ICRP Publication XXX, Annals of the ICRP: Early and late effects of radiation in normal tissues and: threshold doses for tissue reactions and other non-cancer effects of radiation in a radiation protection context (Draft Report for Consultation), January 2011.

International Atomic Energy Agency, International Basic Safety Standards for Protection Againts Ionizing Radiation and for the Safety of Radiastian Sources, Safety Series No. 115, Vienna, Austria, CR-Rom Edition, 2003.

International Atomic Energy Agency, Dosimetry in Diagnostic radiology: An International Code of Practise, Technical Report Series No. 457, Vienna, 2007.

Kementerian Kesehatan Republik Indonesia, 2012. "Data dan Informasi Kesehatan Penyakit Tidak Menular”, ISSN 2088-270X.

Miller, MD., et al, Radiation Doses in Interventional Radiology Procedures: The RAD-IN Study, J Vasc Interv Radio; 14, 2003, 977-990 August 2003. 